\title{
Knowledge, Attitudes, and Usage Related to Dietary Supplements in a Group of Canadian Dental Students: A Pilot Study
}

\section{Jay Hoover $^{1^{*}}$, Hassan Vatanparast ${ }^{2}$, Clinton Chess ${ }^{3}$ and Yasir Daoud ${ }^{3}$}

${ }^{1}$ College of Dentistry, University of Saskatchewan, Saskatoon, SK, Canada

${ }^{2}$ College of Pharmacy and Nutrition/School of Public Health, University of Saskatchewan. Saskatoon, SK, Canada

${ }^{3}$ College of Dentistry, University of Saskatchewan, Saskatoon, SK, Canada

\begin{abstract}
Background: Considering the increasing usage of dietary supplements by the general population, knowledgeable dental practitioners should be able to guide patients concerning the judicial use, efficacy, adverse effects and potential drug interactions of these products. The aim of this study was to determine usage, knowledge, and attitudes related to dietary supplements in a group of Canadian dental students.

Methods: A total of 105 dental students completed a questionnaire consisting of three parts; Demographics and lifestyle; Usage and opinions concerning dietary supplements; and Knowledge concerning micronutrients and deficiency.

Results: Multivitamins and protein powder were most commonly consumed as individual supplements, followed by vitamin C and calcium. Based on the Poisson Regression conducted, there were statistically significant differences in the knowledge of micronutrients between the students of first year and second year $(p=0.0030)$, third year $(p=0.0060)$ as well as the fourth year $(p=0.0190)$. However, there were no statistically significant differences in the knowledge of micronutrients between the students who consumed dietary supplements and those who did not $(\mathrm{p}=0.070)$.

Conclusion: Although dental students at the University of Saskatchewan consume a large number of dietary supplements, knowledge regarding the effects micronutrients have on the body, appeared to be inadequate. This highlights the need to increase content concerning nutrition and dietary supplements within the dental curriculum with the goal of producing well informed oral health personnel, who will be in a better position to effectively counsel patients on diet and nutrition with regards to their oral health.
\end{abstract}

\section{Publication History:}

Received: June 15, 2017

Accepted: August 29, 2017

Published: August 31, 2017

\section{Keywords:}

Knowledge, Attitudes, Usage, Dietary supplements, Dental Students, Canada

\section{Introduction}

A well-balanced diet is essential for the maintenance of overall health and chronic disease prevention and plays a key role in proper dentofacial development [1-3].

The effect of a poor diet on tooth structures is evident in that once teeth have erupted, frequent ingestion of sucrose-containing products could lead to the initiation and progression of dental caries [4]. Further, malnutrition occurring in the first year of life has been linked to an increase in caries in deciduous dentition and may even affect permanent teeth later in life [5].

The effect of nutrition and dietary supplementation on another common oral malady, chronic periodontal disease, is not as clearly defined. Periodontal disease is inflammatory in nature, characterized by clinical attachment loss and destruction of the alveolar bone. The disease is considered to be the main cause of tooth loss in adults [6]. Recently though, an increasing body of evidence from dietary intervention studies has investigated the effect of several macro and micronutrients on the health of the periodontium and on attenuating the disease process [7-10].

For example, a diet consisting of fresh fruits and vegetables, with limited intake of processed foods, reduced gingival inflammation in 20 females with metabolic syndrome [11]. Similarly, supplementing the diet with lycopene and borage seed oil, which contains naturally high levels of gamma-linolenic acid, has also been shown to reduce gingival inflammation [12]. Furthermore, micronutrients such as vitamins $\mathrm{D}$ and $\mathrm{B}$, macronutrients like eicosapentaenoic acid (EPA) and docosahexaenoic acid (DHA), and low dose aspirin have been reported to enhance wound healing after periodontal surgery [13-16].
Besides its role in bone and calcium homeostasis, active vitamin D (1a, 25-dihydroxyvitamin) functions as an immunomodulator because of its anti-inflammatory effect through inhibition of cytokine production by immune cells and stimulation of monocytes and macrophages to secrete peptides with potent antibiotic activity [17]. Therefore, vitamin D supplementation may be beneficial for the treatment of periodontal disease.

Microorganisms involved in periodontal pathology can induce an excessive production of reactive oxygen species (ROS) that could result in the further destruction of the periodontium. The damaging role played by ROS has prompted a search for antioxidant therapy in the treatment of numerous inflammatory conditions including chronic periodontitis. Antioxidants that neutralize ROS may play a vital role in reducing gingival collagen degradation and thereby slow the progression of periodontitis [18]. Coenzyme Q10 is an important antioxidant that is involved in free radical mediated neurodegenerative diseases and also has been shown to be deficient in gingival tissues affected by periodontal disease [19].

Recent intervention studies seem to indicate that supplementation of CoQ10, may be effective as an adjunct in the management of

"Corresponding Author: Dr. Jay Hoover, College of Dentistry, University of Saskatchewan, Saskatoon, SK, Canada; E-mail: j.hoover@usask.ca

Citation: Hoover J, Vatanparast H, Chess C, Daoud Y (2017) Knowledge, Attitudes, and Usage Related to Dietary Supplements in a Group of Canadian Dental Students: A Pilot Study. Int J Clin Nutr Diet 3: 121. doi: https://doi. org/10.15344/2456-8171/2017/121

Copyright: (c) 2017 Hoover et al. This is an open-access article distributed under the terms of the Creative Commons Attribution License, which permits unrestricted use, distribution, and reproduction in any medium, provided the original author and source are credited. 
Citation: Hoover J, Vatanparast H, Chess C, Daoud Y (2017) Knowledge, Attitudes, and Usage Related to Dietary Supplements in a Group of Canadian Dental Students: A Pilot Study. Int J Clin Nutr Diet 3: 121. doi: https://doi.org/10.15344/2456-8171/2017/121

Page 2 of 6

periodontitis when used topically, systemically, or in combination with other synergistic antioxidants such as vitamins $C$ and $E[18,19]$. The available data shows that a balanced diet and/or supplementation with selected macro and micro nutrients, do play a role in the overall health of the oral cavity and in the management of periodontal diseases.

Lately, there has been an exponential growth in the use of dietary supplements and natural health products among the general population in the United States and Canada [20-22]. The wide usage of supplements has resulted in some concern regarding the safety of a few of these products such as Ginkgo Biloba, St.John's wort, Evening primrose and Valerian and their potential interactions with prescribed medication $[23,24]$.

Studies have shown that transition from secondary school to University influences dietary changes among students [25]. Adopting unhealthy eating habits during this critical period could have negative consequences in adulthood, including a higher likelihood of chronic diseases [26]. There is a need to improve knowledge of healthy eating habits among students, which consequently becomes the first step towards awareness on nutrition [27]. Despite that, there have been limited studies evaluating the awareness and behavior of University students towards nutrition

Considering the increasing usage of dietary supplements by the general population, the reported health benefits to the oral cavity, and possible drug interactions, it is imperative that oral health care providers be well informed about their patients' use of over the counter products including nutritional supplements. Knowledgeable healthcare practitioners, including dentists and hygienists, will then be able to guide their patients regarding the judicial use of dietary supplements, advising them on the efficacy and possible adverse effects and drug interactions of some of these products [28][29]. Thus, the purpose of this preliminary study was to determine usage, knowledge, and attitudes related to dietary supplements in a group of Canadian dental students.

\section{Materials \& Method}

All undergraduate dental students enrolled in the Doctor of Dental Medicine (DMD) program at the College of Dentistry, University of Saskatchewan, Saskatoon, Canada were invited to participate in an anonymous, cross-sectional survey conducted during the academic year 2016-17. The survey instrument was similar to a structured questionnaire used in a recent publication that was based on a review of the literature and then standardized after being pilot tested on 25 subjects [30]. Approval to use the questionnaire was obtained from the principal author. The questionnaire included three parts: 1) Demographic details and lifestyle; 2) Usage and opinions concerning dietary supplements; and 3) Knowledge concerning micronutrients and deficiency. The survey was administered to all students in years one through four soon after formal lecture sessions. This allowed flexibility for students to voluntarily complete the survey and increase the response rate. A signed consent form was obtained prior to the distribution of the survey. The completed questionnaire was collected by a clerical staff member of the college of dentistry and stored in a secure location. The survey and the consent form were approved by the Research Ethics Board (REB \#6-251), University of Saskatchewan and conducted anonymously.

\section{Statistical analysis}

Survey data was cleaned and coded in Excel. Data analysis was performed using SPSS version 24. Descriptive statistics were employed to describe socio-demographics, lifestyle practices, usage of dietary supplements and reasons for taking them, as well as opinions regarding such supplements among dental students in all four years of study. Poisson Regression Analysis was used to assess the sociodemographic traits associated with the participants' knowledge, attitudes, and beliefs regarding micronutrients.

\section{Results}

One hundred and five students completed the survey. More than half of the participants were females $(53 \%)$ and $71 \%$ of the respondents were between 20-25 years of age (Table1). A total of $95 \%$ of the students were non-vegetarian, around $88.6 \%$ claimed to never smoke, $47.6 \%$ drank alcohol once a week and $45.7 \%$ exercised occasionally. More than half of the respondents $(62.9 \%)$ indicated that they consumed dietary supplements (Table 2).

\begin{tabular}{|l|l|l|l|}
\hline Variable & & $\mathrm{N}$ & $\%$ \\
\hline \multirow{3}{*}{ Gender } & Male & 49 & 47 \\
\cline { 2 - 4 } & Female & 56 & 53 \\
\hline \multirow{4}{*}{ Age } & $20-25$ years & 75 & 71 \\
\cline { 2 - 4 } & $26-30$ years & 22 & 21.1 \\
\cline { 2 - 4 } & $>30$ years & 8 & 7.9 \\
\hline \multirow{4}{*}{ Current year in dentistry } & 1 & 28 & 26.7 \\
\cline { 2 - 4 } & 2 & 28 & 26.7 \\
\cline { 2 - 4 } & 3 & 24 & 22.9 \\
\cline { 2 - 4 } & 4 & 25 & 23.8 \\
\hline
\end{tabular}

Table 1: Socio-demographic characteristics of study participants $(\mathrm{n}=105)$.

\begin{tabular}{|l|l|l|l|}
\hline Variable & & $\mathrm{N}$ & $\%$ \\
\hline \multirow{4}{*}{ Diet } & Vegetarian & 5 & 4.8 \\
\cline { 2 - 4 } & Non-Vegetarian & 100 & 95.2 \\
\hline Smoking & Never & 93 & 88.6 \\
\cline { 2 - 4 } & Occasionally & 11 & 10.5 \\
\cline { 2 - 4 } & 2-3 times a week & 0 & 0 \\
\cline { 2 - 4 } Consumption & Daily & 1 & 1 \\
\hline \multirow{5}{*}{\begin{tabular}{l} 
Alcohol \\
\cline { 2 - 4 }
\end{tabular}} & Never & 19 & 18.1 \\
\cline { 2 - 4 } & Once a week & 50 & 47.6 \\
\cline { 2 - 4 } & $2-3$ times a week & 32 & 30.5 \\
\cline { 2 - 4 } & $\geq 4 \times$ a week & 2 & 1.9 \\
\hline Exercise & Never & 5 & 4.8 \\
\cline { 2 - 4 } & $\begin{array}{l}\text { Whenever I find } \\
\text { time }\end{array}$ & 37 & 35.2 \\
\cline { 2 - 4 } & $2-3$ times a week & 48 & 45.7 \\
\cline { 2 - 4 } & Daily & 15 & 14.3 \\
\hline Supplements & Yes & 66 & 62.9 \\
\hline
\end{tabular}

Table 2: Distribution of lifestyle practices among study participants $(\mathrm{n}=105)$.

${ }^{\star}$ Missing values: Alcohol consumption $\mathrm{N}=2, \%=1.9$ 
Citation: Hoover J, Vatanparast H, Chess C, Daoud Y (2017) Knowledge, Attitudes, and Usage Related to Dietary Supplements in a Group of Canadian Dental Students: A Pilot Study. Int J Clin Nutr Diet 3: 121. doi: https://doi.org/10.15344/2456-8171/2017/121

Multivitamins, vitamin D, green tea and protein powder were most commonly consumed as individual supplements across the board, followed by a much smaller intake of vitamin C, omega 3 fatty acids and calcium (Figure 1). Figure 2 illustrates the percentage of supplement pairs being consumed. Multivitamins were most commonly consumed together with vitamin $\mathrm{D}$ supplements followed by green tea (Figure 2). Figure 3 shows the reasons for taking supplements. Most participants took supplements to maintain good health (65\%) and to ensure proper nutrition (58\%). The most common sources of information about dietary supplements were obtained via the internet (59\%) followed by family members, doctors, and friends (Table 4). The participants were also asked to express their opinion concerning the use of supplements (Figure 4) by agreeing, disagreeing or indicating as 'unsure' to certain statements. More than $40 \%$ of the students who consumed supplements either agreed strongly' or 'agreed' that 'supplements are not necessary as long as you have a healthy eating habit, meeting the recommended allowance' while 53\% disagreed with the statement that 'dietary supplements are necessary for all ages'. Between $40-50 \%$ were not sure if the 'regular use of supplements prevented chronic diseases or cancer'. 'Figure 5 demonstrates the percentage score of knowledge concerning micronutrients in students in each of the four years and differences between the genders. The bars represent the average percentage of correct answers by male and female students in four years separately. Based on the Poisson Regression conducted, there were statistically significant differences in the knowledge of micronutrients between males and females in first year and second year $(\mathrm{p}=0.0030)$ only. However, there were no statistically significant differences in the knowledge of micronutrients between the students who consumed dietary supplements and those who did not $(\mathrm{p}=0.070)$.

\begin{tabular}{|l|l|l|}
\hline Internet & 39 & $59 \%$ \\
\hline Family & 28 & $42 \%$ \\
\hline Doctor & 26 & $39 \%$ \\
\hline Friends & 23 & $35 \%$ \\
\hline Formal books & 15 & $23 \%$ \\
\hline Workshops/ Discussion/ Lectures & 9 & $14 \%$ \\
\hline Magazines/ Newspapers & 3 & $5 \%$ \\
\hline Television/ Radio & 1 & $2 \%$ \\
\hline
\end{tabular}

Table 3: Sources of information about dietary supplements $(n=105)$; multiple response.

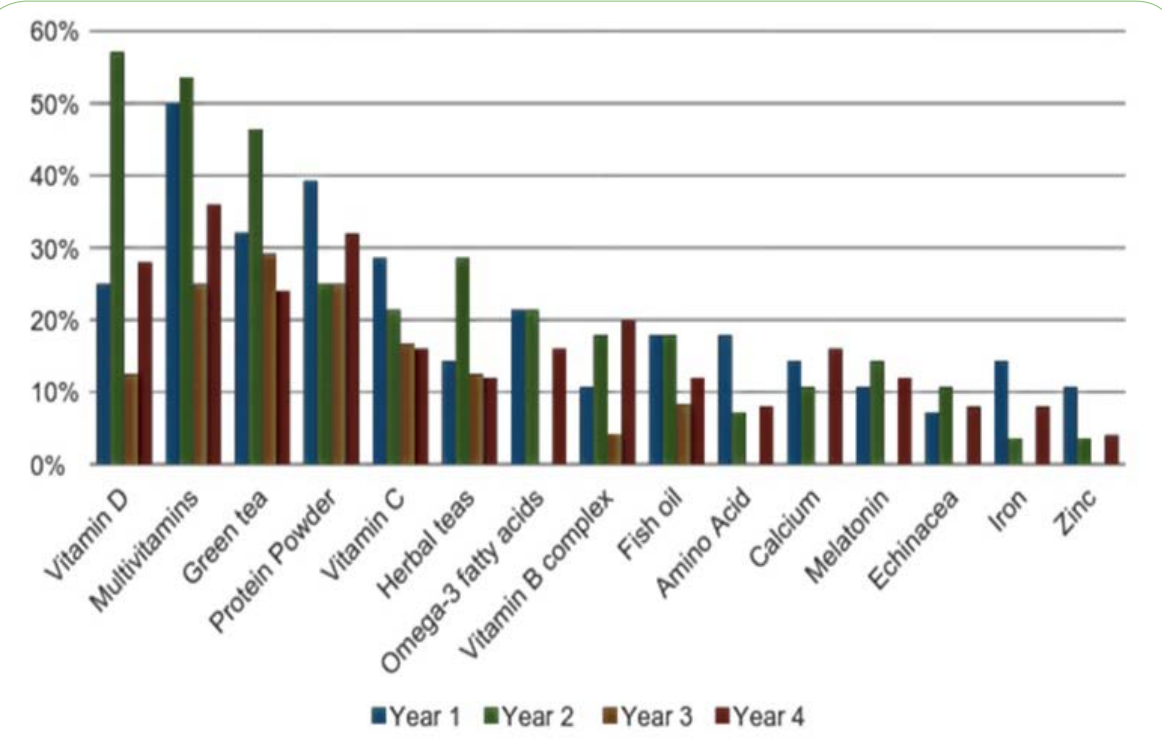

Figure 1: Percentage of students consuming supplements by year of study.

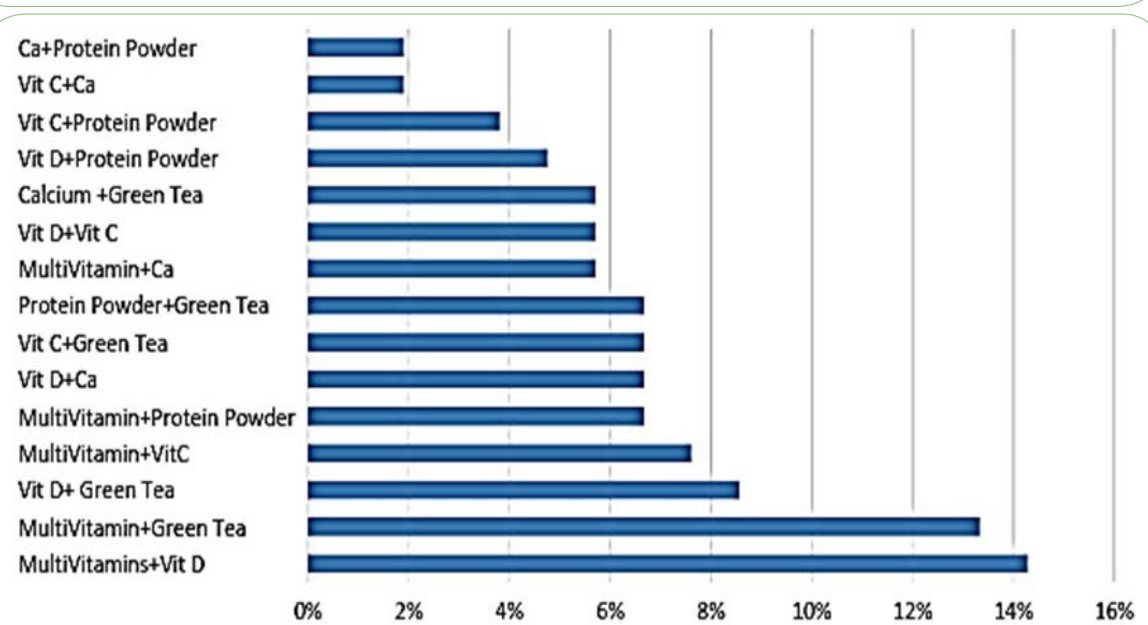

Figure 2: Percentage of supplement pairs being consumed. 
Citation: Hoover J, Vatanparast H, Chess C, Daoud Y (2017) Knowledge, Attitudes, and Usage Related to Dietary Supplements in a Group of Canadian Dental Students: A Pilot Study. Int J Clin Nutr Diet 3: 121. doi: https://doi.org/10.15344/2456-8171/2017/121

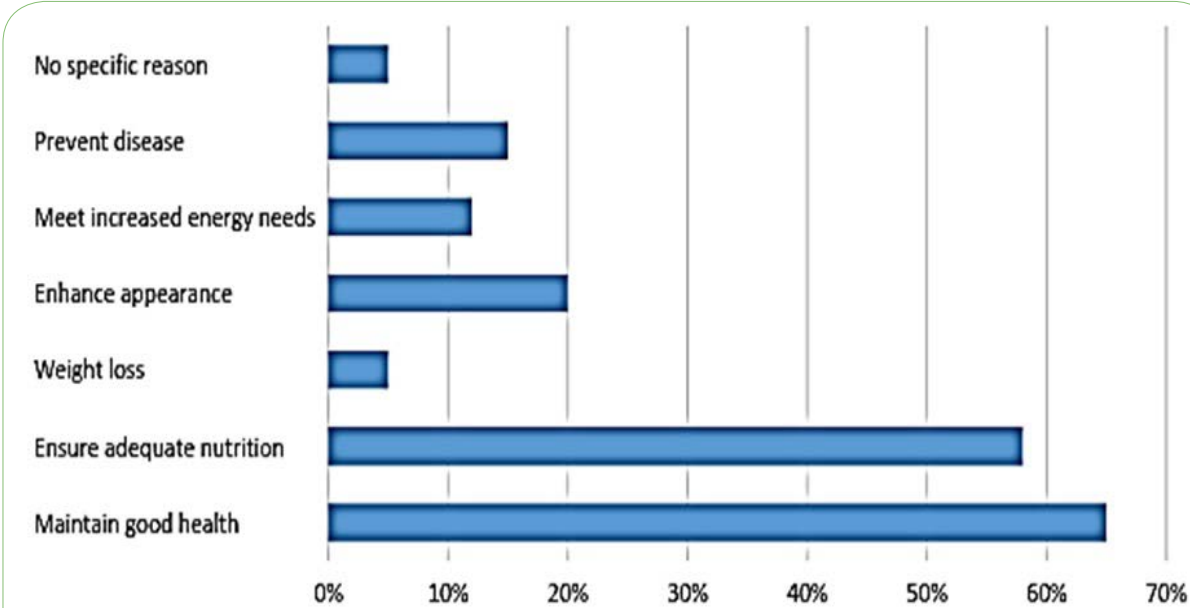

Figure 3: Reasons for taking dietary supplements; multiple response.

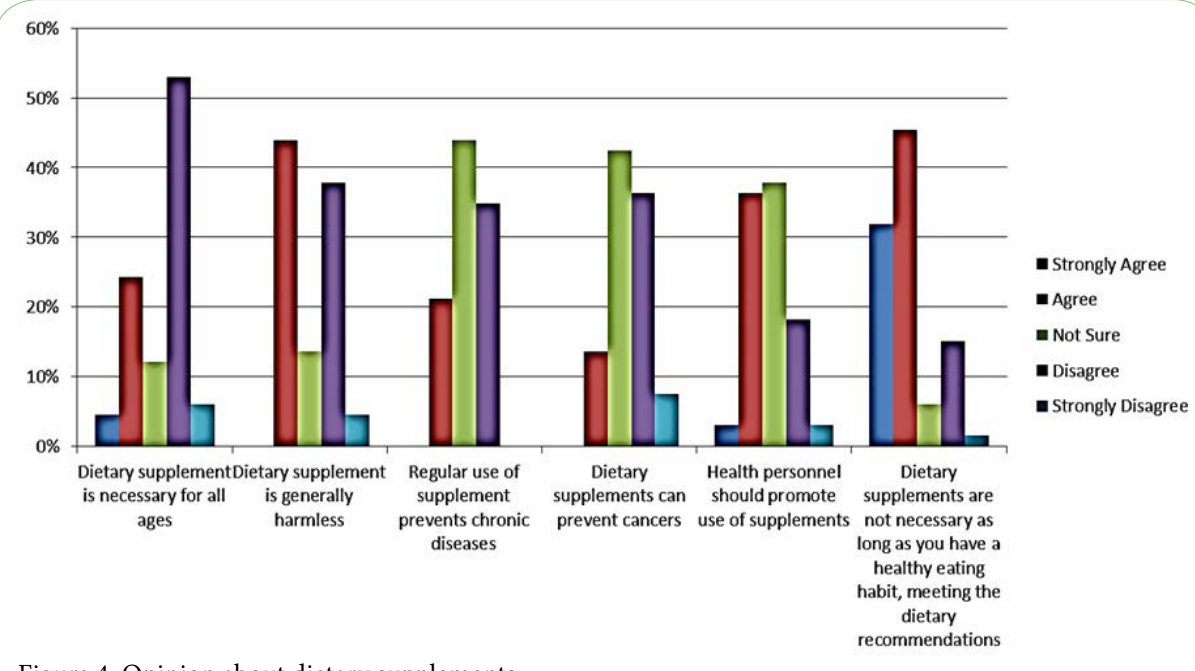

Figure 4: Opinion about dietary supplements.

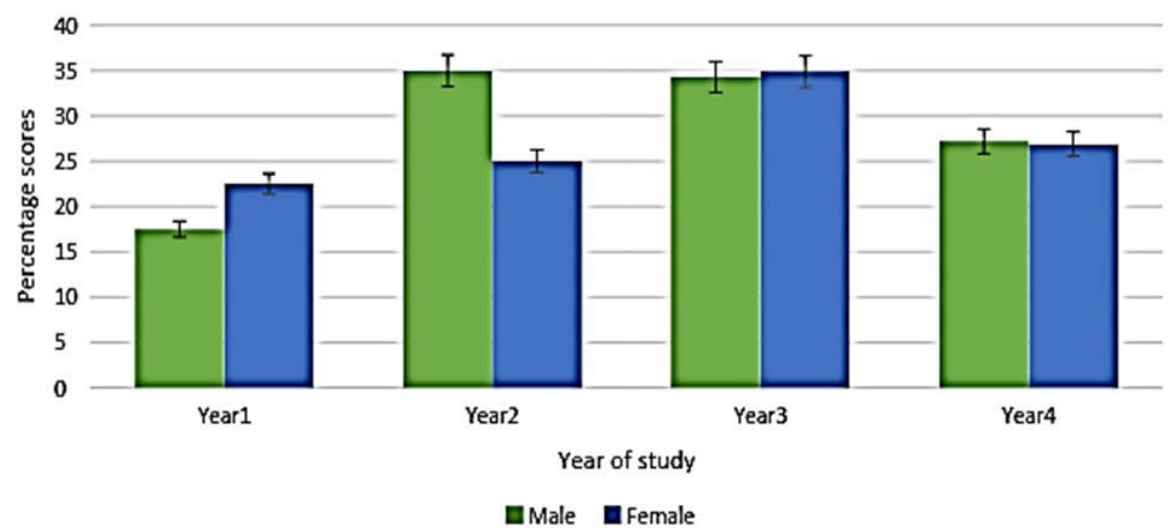

Figure 5: Percentage score of Knowledge concerning Micronutrients.

\section{Discussion}

There is a growing body of evidence to indicate that selected macro and micronutrients, in sufficient levels, are not only essential for the development of tooth structures but may also play a role in modifying the progression and treatment outcomes of periodontal disease [8,31]. Further, the increasing use of dietary supplements by the general public and the possibility of interactions with prescription medication make it imperative that oral health providers be erudite about the role of nutrition in the general and oral health of their patients. This pilot study was therefore, conducted to obtain an understanding of the knowledge and use of dietary supplements in a group of dental students attending a university in Western Canada. More than half of the young adults in the present study claimed to currently consume dietary supplements, with $36 \%$ of these students taking multivitamins by itself. It was interesting to note that while multivitamins, green 
tea and protein powder were a popular choice as supplements taken individually across all years of study, less than $30 \%$ of students in years 1,3 and 4 consumed vitamin D by itself, and only $7 \%$ took calcium along with vitamin $\mathrm{D}$.

Less than $20 \%$ of students in all years of study consumed calcium supplements or omega 3 fatty acids and almost none of the respondents took Coenzyme Q10, despite their well established benefits to the general health and recent evidence suggesting that supplementing the diet with CoQ10, and omega fatty acids, may be effective as an adjunct in the of maintaining a healthy mouth $[15,19]$.

The Canadian Community Health Survey (CCHS) Cycle 2.2 data, a nationwide cross-sectional nutrition survey carried out in 2004-2005 revealed that about $40 \%$ of Canadians used supplements in general while $28 \%$ used three or more supplements $[32,33]$. Vatanparastet al. [33] analyzing the same CCHS dataset, reported that the use of supplements was higher among older adults (over 50 years of age), in females, and among those living in high-income households. The relatively high use of supplements in the current sample of young adults enrolled as students in a dental school may be due to the higher level of education among these individuals, a finding also supported by data from the CCHS study [34]. The majority of the participants in the present study practiced healthy lifestyle habits such as not smoking, limiting alcohol consumption, and engaging in exercise 2-3 times a week or more. Dietary supplement users, in general, tend to maintain lifestyle practices conducive to healthy living [34][35]. The supplements most commonly used in the present study were multivitamins and protein powder. Other studies investigating health science students living in diverse geographical locales report a higher consumption of vitamins A and B complex [30]. It was important to consider the low intake of vitamin $\mathrm{D}$ in the present study, despite the educational efforts aimed at the public to increase consumption of vitamin $\mathrm{D}$ through diet and/or supplements, especially during the long, dark Canadian winters [36]. Interestingly, less than $2 \%$ of our subjects indicated taking calcium supplements. According to Osteoporosis Canada, osteoporosis-related fractures are more common than heart attack, breast cancer, and stroke, combined [37]. Inadequate dietary calcium intake has been implicated in osteoporosis and osteoporosisassociated fractures [38]. There is a need to establish lifelong dietary habits in childhood and adolescence, prior to a peak onset of bone mineral accrual [39]. Almost half, $44 \%-61 \%$ of Canadian adults are not getting recommended amounts of calcium $(1000 \mathrm{mg} / \mathrm{d})$ [40], and is supported by the observations made in the current study.

Bailey et al. [41] reported that supplement users were motivated to use these products for overall health more commonly than for supplementing nutrients from food intakes. Less than a quarter of supplements used by adults were recommended by a physician or health care provider, while in the present study 39\% reported obtaining information on recommendation to take supplements from a physician. Over $50 \%$ of the dental students who took dietary supplements did not agree that supplements are necessary for all age groups and more than $40 \%$ were in agreement that supplements were harmless. More than $40 \%$ of those who consumed supplements were uncertain if supplements could prevent chronic diseases or cancers.

There was an ambiguity in the present study, in relation to the statement; "healthcare personnel should promote the use of supplements" as nearly thirty percent were in agreement and an equal number were not certain. Teng et al. [28], also observed similar results in a group of health science students in Malaysia. Regarding knowledge of micronutrients, approximately only one-third of the questions were answered correctly by the current participants. In general, although more than half of the dental students surveyed claimed to use supplements, their opinion and knowledge concerning these supplements were inadequate. The authors are not certain as to why there was no differences in the knowledge of micronutrients between those who did and did not consume the supplements. It is likely that those who did consume nutrients did so simply based on the recommendation of a health care provider, friend or even the media. The general lack of knowledge emphasizes the need for incorporating nutrition as a topic in the dental curriculum. A recent study conducted at Manipal University in India [30] demonstrated an overall lack of knowledge of nutritional supplements across a group of medical, dental and nursing students with medical students having a greater knowledge compared to their dental counterparts. The current curriculum of Canadian dental students at this locale has only a small nutrition component and this is probably the case among dental students at Manipal University in India, probably reflecting the inadequate knowledge in these students attending two geographically different locales. Comparable outcomes were also reported among a group of patients attending a dental clinic in Virginia, USA [23].The genders were compared in order to ascertain if there were differences in knowledge concerning nutrition supplements among males and female dental students attending institutions in two very different sites (Canada and India). Interestingly, there was no statistically significant difference in knowledge between male and female dental students either at the University of Saskatchewan, Canada or in Manipal University, India [30].

\section{Limitations}

The study surveyed all students attending the College of Dentistry at the University of Saskatchewan. However, due to the small annual intake of students, the sample size was relatively small, and the results, therefore, cannot be assumed to represent students in other dental schools in Canada. Further, self-reported responses are subject to reporting bias and error which could lead to over or underreporting due to misinterpretation of the questions [42].

\section{Conclusions}

It is evident that a significant proportion of dental students at the University of Saskatchewan claim to consume a large number of dietary supplements. Despite this, an understanding of the effects micronutrients have on the body appeared to be inadequate. Similar results have been observed among health science students in diverse geographical locales such as India and Malaysia. Considering the increasing prevalence of dietary supplement users, the potential interactions with prescribed medications and emerging data on their effect on periodontal disease, it is recommended that educators incorporate and emphasize the importance of nutrition within dental curriculums. The objective would be to graduate well informed oral health personnel, who will be in a position to effectively counsel patients on diet and nutrition with regards to their oral health.

\section{Competing Interests}

The authors declare that they have no competing interests.

\section{Author Contributions}

J. Hoover: Made substantial contributions to the conception, design, and the drafting of the manuscript. 
Citation: Hoover J, Vatanparast H, Chess C, Daoud Y (2017) Knowledge, Attitudes, and Usage Related to Dietary Supplements in a Group of Canadian Dental Students: A Pilot Study. Int J Clin Nutr Diet 3: 121. doi: https://doi.org/10.15344/2456-8171/2017/121

H. Vatanparast: Involved in analysis and interpretation of data and revising the manuscript critically on important intellectual contents.

C.Chess: Made significant contributions towards the acquisition of data and the drafting of the manuscript.

Y.Daoud: Made significant contributions towards the acquisition of data and the drafting of the manuscript.

\section{Funding}

The Funding was provided by the College of Dentistry, University of Saskatchewan.

\section{References}

1. Diet, nutrition and the prevention of chronic diseases, Report of the join WHO/FAO expert consultation. WHO Technical Report Series, No. 916 (TRS 916).

2. Willett WC, Koplan JP, Nugent R, Dusenbury C, Puska P, et al. (2006) Prevention of Chronic Disease by Means of Diet and Lifestyle Changes. Chapter 44.

3. Tyszkowski, M (2016) There a Relationship between Nutrition, Facia Development, and Crowding of the Teeth? Int J Orthod Milwaukee 27: 1517.

4. Anderson CA, Curzon ME, Van Loveren C, Tatsi C, Duggal MS (2009) Sucrose and dental caries: a review of the evidence. Obes Rev 10: 41-54.

5. Alvarez JO (1995) Nutrition, tooth development, and dental caries. Am J Clin Nutr 61: 410S-416S

6. Locker D, Ford J, Leake JL (1996) Incidence of and risk factors for tooth loss in a population of older Canadians. J Dent Res 5: 783-789.

7. Meisel P, Schwahn C, Luedemann J, John U, Kroemer HK, et al. (2005) Magnesium deficiency is associated with periodontal disease. J Dent Res 84: $937-941$

8. Johnston BD, Fritz PC, Ward WE (2013) Use of Dietary Supplements in Patients Seeking Treatment at a Periodontal Clinic. Nutrients 5: 1110-1121.

9. Iwasaki M, Yoshihara A, Moynihan P, Watanabe R, Taylor GW, et al. (2010) Longitudinal relationship between dietary $\mathrm{u}-3$ fatty acids and periodontal Disease. Nutrition: 26: 1105-1109.

10. Nanayakkara V, Ekanayake L, Silva R (2014) Dietary intake of calcium vitamins $A$ and $E$ and bleeding on probing in Sri Lankan preschoolers. Comm Dental Health 31:153-157.

11. Jenzsch A, Eick S, Rassoul F, Purschwitz R, Jentsch H (2009) Nutritional intervention in patients with periodontal disease: Clinical, immunological and microbiological variables during 12 months. Br J Nutr 101: 879-885.

12. Chandra RV, Prabhuji ML, Roopa DA, Ravirajan S, Kishore HC (2007) Efficacy of lycopene in the treatment of gingivitis: A randomised, placebocontrolled clinical trial. Oral Health Prev Dent 5: 327-336.

13. Bashutski JD, Eber RM, Kinney JS, Benavides E, Maitra S, et al. (2011) The impact of vitamin D status on periodontal surgery outcomes. J Dent Res 90: 1007-1012.

14. Barroso AB, Lima V, Guzzo GC, Moraes RA, Vasconcellos MC, et al. (2016) Efficacy and safety of combined piroxicam, dexamethasone, orphenadrine, and cyanocobalamin treatment in mandibular molar surgery. Braz $\mathrm{J}$ Med Biol Res 39: 1241-1247.

15. Elkhouli AM (2011) The efficacy of host response modulation therapy (omega-3 plus low-dose aspirin) as an adjunctive treatment of chronic periodontitis (clinical and biochemical study). J Periodontal Res 46: 261 268.

16. Lau BY, Johnston BD, Fritz PC, Ward WE (2013) Dietary Strategies to Optimize Wound Healing after Periodontal and Dental Implant Surgery: An Evidence Based Review. Open Dent J 7: 36-46.

17. Garcia MN, Hildebolt CF, Miley DD, Dixon DA, Couture RA, et al. (2011) One-year effects of vitamin $D$ and calcium supplementation on chronic periodontitis. J Periodontol 82: 5-32.

18. Prakash S, Sunitha J, Hans M (2010) Role of coenzyme Q10 as an antioxidant and bioenergizer in periodontal diseases. Indian J Pharmacol 42: 334-337.
19. Manthena S, Rao MV, Penubolu LP, Putcha M, Harsha AV (20135) Effectiveness of CoQ10 Oral Supplements as an Adjunct to Scaling and Root Planing in Improving Periodontal Health. J Clin Diagn Res 9: ZC26ZC28.

20. Dickinson A, Blatman J, El-Dash N, Franco JC (2014) Consumer Usage and Reasons for Using Dietary Supplements: Report of a Series of Surveys. Jo Am Coll Nutr 33: 176-182.

21. Canadian Community Health Survey, Cycle 2.2, Nutrition (2004) A Guide to Accessing and Interpreting the Data (Catalogue H164-20/2006E-PDF).

22. Radimer K, Bindewald B, Hughes J, Ervin B, Swanson C, et al. (2004) Dietary Supplement Use by US Adults: Data from the National Health and Nutrition Examination Survey, 1999-2000. Am J Epidemiol 160: 339-449.

23. BakuriS (2014) "The Reporting of Supplement Use by Dental Patients on Their Medical History Questionnaire." VCU Scholars Compass. Virgina Commonwealth University.

24. Fitzgerald J, Epstein JB, Donaldson M, Schwatz G, Jones C, et al. (2015) Outpatient medication use and implications for dental care: Guidance for contemporary dental practice. J Can Dent Assoc 81: f10.

25. Deliens T, Clarys P, De Bourdeaudhuij I, Deforche B (2014) Determinants of eating behaviour in university students: a qualitative study using focus group discussions. BMC public health 14: 53

26. Cooke R, Papadaki A (2014) Nutrition label use mediates the positive relationship between nutrition knowledge and attitudes towards healthy eating with dietary quality among university students in the UK. Appetite 83: 297-303.

27. Tanton J, Dodd LJ, Woodfield L, Mabhala M (2015) Eating behaviours of British university students: a cluster analysis on a neglected issue. Advances in preventive medicine 2015: 639239.

28. Teng CL, Tey KK, Lim PH, Cheng SF, Nordin MS, et al. (2008) Dietary supplements: usage and opinions among health sciences students. leJSME 2: 30-32.

29. Gardiner P, Woods C, Kemper KJ (2006) Dietary supplement use among health care professionals enrolled in an online curriculum on herbs and dietary supplements. BMC Complement Altern Med 6: 21.

30. Sharma A, Adiga S, Ashok M (2014) Knowledge, Attitude and Practices Related to Dietary Supplements and Micronutrients in Health Sciences Students. J Clin Diagn Res 8: HC10-HC13.

31. Van der Velden U, Kuzmanova D, Chapple IL (2011) Micronutritional approaches to periodontal therapy. J Clin Periodontol 38: 142-158.

32. Shakur YA, Tarasuk V, Corey P, O'Connor DL (2012) A comparison of micronutrient inadequacy and risk of high micronutrient intakes among vitamin and mineral supplement users and nonusers in Canada. J Nutr142: 534-540.

33. Vatanparast $\mathrm{H}$, Adolphe $\mathrm{JL}$, Whiting SJ (2010) Socio-economic status and vitamin/mineral supplement use in Canada - Statistics Canada, Catalogue no. Health Rep 21: 19-25.

34. J Ishihara, T Sobue, S Yamamoto, S Sasaki, S Tsugane (2003) Demographics, lifestyles, health characteristics, and dietary intake among dietary supplement users in Japan. Int J Epidemiol32: 546-553.

35. Foote JA, Murphy SP, Wilkens LR, Hankin JH, Henderson BE, Kolonel LN (2003) Factors associated with dietary supplement use among healthy adults of five ethnicities: the Multiethnic Cohort Study. Am J Epidemiol 157: 888-897.

36. Whiting SJ, Langlois KA, Vatanparast H, Greene-Finestone LS (2011) The vitamin D status of Canadians relative to the 2011 Dietary Reference Intakes: an examination in children and adults with and without supplement use. Am J ClinNutr 94: 128-35.

37. "What Is Osteoporosis?" Osteoporosis Canada. N.p., 2016.

38. Ross AC, Manson JE, Abrams SA, Aloia JF, Brannon PM, et al. (2011) The 2011 report on dietary reference intakes for calcium and vitamin D. Public Health Nutrition 14: 938-939.

39. Ontario Health Promotion E-Bulletin, 19 February 2016 - OHPE Bulletin 925, 2016: 925

40. Vatanparast H., Dolega-Cieszkowski JH, Whiting SJ (2009) Many adult Canadians are not meeting current calcium recommendations from food and supplement intake. Appl Physiol Nutr Metab 34: 191-196.

41. Bailey RL, Gahche JJ, Miller PE, Thomas PR, Dwyer JT (2013) Why US adults use dietary supplements. JAMA Intern Med173: 355-361.

42. Fadnes L, Taube A, Tylleskär T (2008) How to identify information bias due to self-reporting in epidemiological research. The Internet Journal of Epidemiology 7: 2 . 